\title{
Modern variety breeding for present and future needs
}

\author{
Jaime Prohens
}

Published online: 21 August 2009

(C) Springer Science+Business Media B.V. 2009

The 18th General Congress of the European Association for Research on Plant Breeding (EUCARPIA) took place from September 9 to 12 in Valencia, Spain. Previous meetings were held in Austria (Tülln, 2004) and in the United Kingdom (Edinburgh, 2001), and the next EUCARPIA General Congress will take place in Hungary (Budapest, 2012). General Congresses are the most important scientific events of EUCARPIA and, in this case, more than 420 participants registered for the 18th EUCARPIA General Congress. Participants represented breeders and breeding researchers from 44 European and overseas countries and joined the 4 days programme, which included four invited conferences, 32 plenary lectures, and 286 poster presentations. The topic of this 18th General Congress was "Modern variety breeding for present and future needs", stressing the importance of using modern approaches for developing new varieties adapted to the present, but also to the foreseeable needs. The logo of the Congress was a cornucopia (horn of abundance) representing the success of the past and present (and hopefully future) breeders in delivering cultivars that have allowed obtaining abundant supplies of plant products for human needs even though human population has

J. Prohens $(\square)$

Instituto de Conservación y Mejora de la Agrodiversidad Valenciana, Universidad Politécnica de Valencia, Camino de Vera 14, 46022 Valencia, Spain

e-mail: jprohens@btc.upv.es increased dramatically in the last century. Because the objectives and tools of breeding and the methods used are very diverse, the topics addressed were divided into four plenary sessions: (1) "Conservation of genetic resources and prebreeding", (2) "Breeding for yield and resistance to biotic and abiotic stresses", (3) "Breeding for quality", and (4) "Evaluation and release of breeding material and new breeding objectives".

The conveners of the Congress, Prof. J. Prohens (President of EUCARPIA) and Dr. M. L. Badenes (Secretary General of EUCARPIA), together with the Rector of the Polytechnical University Valencia and the Secretary of the Agricultural Ministry of the Regional Government opened the Congress on September 9 afternoon in the Congress hall, which was situated in the Polytechnical University of Valencia.

In the following first session, entitled "Conservation of genetic resources and prebreeding", which was chaired by A. Börner and B. Boller, A. Börner, from the Leibniz Institut of Plant Genetics and Crop Plant Research of Gatersleben, gave an invited conference on "Plant genetic resources for future breeding" in which he presented the status and challenges of ex situ plant genetic resources conservation, as well as the strategies for maintenance and management of germplasm. Subsequently, there were several presentations on the status, gaps and challenges in wild relatives of lettuce and their relevance for breeding (A. Lebeda), the demonstration that selected ecotypes of Italian ryegrass can outperform 
current recommended cultivars (B. Boller), the importance of the role crop/pollinator relationship in breeding legume varieties (R. G. Palmer), the utility of high throughput genotyping for the characterization of barley germplasm (N. Rostoks), the use of statistical tools for genomic prediction of breeding values in modern varieties (M. Bink), and the use of wheat genetic resources at CIMMYT for broadening the genetic base of modern varieties (M. Zaharieva).

The second session "Breeding for yield and resistance to biotic and abiotic stresses" was held on Wednesday 10 September and was the session with a greater number of oral presentations. It was chaired by R. Tuberosa and Z. Bedö during the morning and by G. Smant during the afternoon. The invited conference was given by R. Tuberosa from the University of Bolonia and was entitled "Genomics approaches to improve tolerance to biotic and abiotic stresses". This conference focused on the advances that can be achieved by using genomic tools and approaches in the breeding of crops for resistance to environmental stresses, including a more intense exploitation of genetic resources, novel mapping approaches and genetic materials, and platforms for facilitating the identification and cloning of QTLs. After this lecture, there were eight oral contributions that dealt with the use of Prunus genomics resources and their application to translational breeding (A. Abbott), the identification of genes of resistance to leaf rust in wheat as well as of markers associated to these genes (G. Vida), the use of molecular markers for screening QTLs for late blight resistance in potato (E. Ritter), the strategies and results in breeding for stability across increasingly variable environments (M. Wolfe), the combination of traditional and modern approaches for developing early-maturing hybrids of maize (M. Carena), the use of synthetic hexaploids and derivatives as sources of germplasm for improving the biotic and abiotic stress tolerance in wheat (F. Ogbonnaya), the test-cross performance of double-haploid lines from European flint maize landraces (H. H. Geiger), and the use of molecular markers in dissecting the biomass yield in perennial ryegrass (S. Barth). This session was continued in the afternoon with the BIOEXPLOIT Symposium "Exploitation of natural plant biodiversity for the pesticide-free production of food", in which there were five oral presentations on the BIOEXPLOIT project and activities in disease resistance breeding in potato and wheat (G. Smant), the implications for wheat breeding of the longdistance spread of aggressive yellow rust (M. S. Hovmøller), the strategies for reducing the yield penalty of the resistance of wheat to septoria tritici blotch (J. K. M. Brown), the importance of the understanding of the molecular mechanisms underlying the resistance to plant diseases (F. Takken), and the use of molecular marker technologies in resistance gene pyramiding (A. P. Sorensen).

The third session "Breeding for quality" took place on September 11 and was chaired by R. Visser and J. Vollmann. The invited conference, which was given by R. Visser from the University of Wageningen, was entitled "Breeding for quality in crop plants using genomic tools", and illustrated the interest and importance of genomic tools in achieving considerable advances in complex quality breeding objectives in several crops, like brassicas, tomato and potato. The invited conference was followed by seven oral presentations which dealt with the development of markers and association mapping for improving malting quality in barley (I. Matties), the use of genomic approaches to breeding for preharvest sprouting in rye (P. Masojć), the progresses made and challenges in the molecular breeding for yield and quality in oilseed crops (W. Friedt), the modeling of various types of phenotypic traits in terms of underlying QTLs associated to quality traits in tomato using a wide range of statistical tools (F. van Eeuwijk), the QTL mapping of alpha acid content in hop (A. Cerenak), the genetics of dietary fibre in wheat (G. Charmet), and the breeding for antioxidant phenolic compounds in pepper and eggplant (A. Rodríguez-Burruezo).

The last session, which took place on September 12, was devoted to "Evaluation and release of breeding material and new breeding objectives". This session was chaired by $Y$. Barrière and J. Bradshaw. The invited conference was entitled "Genetic and genomic approach for improving biofuel production from maize" and was imparted by Y. Barrière, from the INRA of Lusignan. This conference showed that the sustainable production of biofuels from maize will benefit from the use of cell wall carbohydrates in the production of these fuels. In this respect, it was stressed that it is necessary to use a wide range of genetic and genomic tools to understand the cell wall composition and set up in 
order to have an efficient biofuel production from maize. Following this invited conference there were other six oral presentations dealing with the manipulation of flowering time for improving yield, quality and stress resistance in crop plants (C. Jung), the breeding, based on genetic resource utilization and molecular markers, of Calluna vulgaris, an ornamental crop ( $\mathrm{T}$. Borchert), the cisgenesis, as a new approach for introgression breeding (E. Jacobsen), the risks of viral protein transcomplementation in virus-resistant transgenic plants (J. Latham), the use of genotypic recurrent selection for the improvement of yield, processing quality and disease resistance in potato (J. Bradshaw), and the benefits and inconvenient of intellectual property rights and access rules for germplasm (H. Ghijsen).

These oral presentations, which had a high scientific level, were selected by the scientific committee among the contributions submitted based on a number of criteria, including the preference of the authors, the interest for the broad audience attending the Congress, the scientific relevance of the contributions, the adaptation of the contents to the sessions established, and also an adequate representation of crops and subjects in order to provide a broad view of the status and trends of plant breeding in order to develop new varieties.

Additionally to the four oral sessions, two poster sessions (one on September 9 and 10, and the other on September 11 and 12) were organized. These poster sessions gave the opportunity to display and discuss the great range of breeding activities of the international community of breeders.

During the closing ceremony, the retiring president Prof. J. Prohens introduced the newly elected president for the period from 2008 until 2012, Prof. Z. Bedo, who invited cordially the Congress delegates and all other EUCARPIA members and breeders for the next General Congress to be held in Hungary in 2012.

The proceedings book, which has 729 pages and includes all the contributions presented was made available to the participants at the beginning of the congress. All the published contributions had been formerly reviewed by the scientific committee. Many thanks are due to the scientific committee, which did an outstanding work in reviewing all the contributions and suggesting changes for improvement in many of them, as well as in selecting the presentations to be presented orally.

This special issue of Euphytica, which includes peer reviewed full papers of some of the most relevant works presented at the Congress, has been published as an outcome of the Congress. Most prominent scientists from all around the world kindly acted as reviewers to guarantee the scientific quality of the papers of this special issue. I wish to thank the authors, guest editors, as well as the Euphytica staff, for the production of this special issue, which will give greater relevance to some of the presentations given at the 18th EUCARPIA General Congress.

Finally, I wish to mention that the organizing committee and all the students and young researchers that collaborated in the Congress did an excellent job, which contributed to the success of the 18th EUCARPIA General Congress. I would also like, in the name of the EUCARPIA president Dr. Zoltán Bedö, to invite you to the 19th EUCARPIA General Congress that will be held in Budapest, Hungary in 2012. 